\title{
Supporting Emergency Remote Teaching Due to Coronavirus Pandemic: Problem Solving Group at ICUDDR
}

HENRIQUES, S. ${ }^{1}$, HOPKINS EYLES, ${ }^{2}{ }^{2}$

1 | Universidade Aberta, University Institute of Lisbon, Centre for Research and Studies in Sociology, Lisboa, Portugal

2 | International Consortium of Universities for Drug Demand Reduction
Citation | Henriques, S., \& Hopkins Eyles, C. (2021). Supporting emergency remote teaching due to coronavirus pandemic: Problem Solving Group at ICUDDR. Adiktologie, 21(4), 211-218. https://doi.org/10.35198/01-2021-004-0001
BACKGROUND: The COVID-19 pandemic has been challenging for all and has had a particular effect on university-level educators. Although the use of technologies in education is recognized as critical in developing transversal skills and preparing students for the needs of modern society, the COVID-19 pandemic crisis stressed the relevance of the digital medium. At the same time, the emergency hastened significant changes to universities' main roles - teaching, learning, and evaluation. AIMS: In this article, we present research conducted by a Problem-Solving Group, a virtual community of practice formed by the International Consortium of Universities for Drug Demand Reduction (ICUDDR) to support educators in addressing the challenges of the pandemic crisis. METHODS: Based on a problem-solving methodology, the virtual community of practice (Problem-Solving Group) provided synchronous group sessions and asynchronous individual support. The resulting analysis and discussion are based on the problem- solving methodology. PARTICIPANTS: Twenty-two educators, including two facilitators, attended six virtual problem-solving sessions between September and December 2020. RESULTS: Participants were committed educators who shared their experiences, challenges, and best practices. The problem-solving methodology was effective in identifying critical areas in remote emergency university-level teaching. CONCLUSIONS: The results stress the importance of creating a common space where educators with similar problems and difficulties can share ideas, experiences, and best practices. The virtual community of practice was effective, although it requires more extensive development and research.

\section{Keywords | Online Learning - Virtual Community of Practice - Problem Solving Methodology}




\section{BACKGROUND}

The COVID-19 pandemic has been very challenging for all and has had a significant impact on educators at the university level. Although the use of technologies in education is recognized as very important in developing transversal skills and preparing students for the needs of modern society, the COVID-19 pandemic crisis stressed the relevance of the digital medium (Moreira, Henriques \& Barros, 2020a; Stoll, 2020). At the same time, the emergency hastened significant changes to the universities' main roles: teaching, learning, and evaluation (OECD, 2020; Stoll, 2020; Shahzad et al., 2020).

The online education market size is expected to grow at a compound annual growth rate of 28.55\% from 2019 to 2023 (Market Research Future, 2020). Technologies have been changing traditional ways of teaching and learning. Most universities provide online courses for their students on and off-campus, and it is expected that teaching and learning models will change significantly in 10 to 15 years (Shahzad et al., 2020). Due to the massive growth of internet and digital technologies, as well as learning and teaching models, how learners relate to each other and to content are already changing significantly with the use of intellectual capital and artificial intelligence (Alvino et al., 2020; Di Vaio et al., 2020).

The COVID-19 pandemic and subsequent safety precautions rapidly changed operating conditions, with constantly changing effects on all dimensions - industry, trade, culture, health systems, civic activity, education, and teaching. Colleges and universities had a short time to design ways to continue instruction activities while keeping their staff and students safe from a public health emergency. The lockdown led to almost all institutions to move their face-to-face classes online (Moreira, Henriques \& Barros, 2020; Dias-Trindade, Correia \& Henriques, 2020; Hodges et al., 2020).

Online learning can enable flexibility, blurring boundaries of time and space. However, the unprecedented speed of this change left little or no time for preparation, requiring instructors to become "instructional MacGyvers," using the expression of Hodges et al. (2020). In addition, staff needed to learn how to implement online learning, which meant using technological devices with pedagogical intentionality (Moreira et al., 2020b). For these reasons, Hodges et al. (2020) propose a new concept for the "type of instruction being delivered in these pressing circumstances: emergency remote teaching."

Emergency remote teaching describes courses offered online in response to a crisis or disaster. The primary objective in these circumstances is to provide temporary access to instruction and instructional supports in a manner that is quick to set up and is reliably available during an emergency or crisis. In contrast, digital network education is a robust educational ecosystem based on well-planned online learning experiences with the innovative use of digital tools and technologies supporting pedagogical strategies during teaching and learning (Hodges et al., 2020). Although this is an important conceptual distinction, educators operating under critical conditions such as the COVID-19 pandemic need more acute support than specialized institutional teams can offer (Hodges et al., 2020; Moreira et al., 2020a, 2020b).

Supporting educators under these stressful conditions has two purposes. On one hand, it gives them the needed assistance in responding to difficulties, doubts, problems, and vulnerabilities. On the other hand, it helps educators gradually improve their pedagogical practices. The COVID-19 pandemic and its aftermath are expected to affect education moving forward (UNESCO, 2020). Thus, researchers, universities, businesses and policymakers, educators, and communities must be aware that "... we cannot return to the world as it was before" (UNESCO, 2020a, p. 3).

The Global Education 2030 Agenda of UNESCO (2020b) includes quality of education through inclusion and equity, and promoting lifelong learning opportunities for all, among its aims. In this context, "... more attention is necessary on how technology and learning can be integrated effectively, including the vital role of teachers, and the student's needs" (Ferri, Grifoni \& Guzzo, 2020 , p. 2). The challenges emerging from the pandemic crisis can improve online learning and evolving educational models, thus overcoming inequalities and social exclusion.

Collaboration and networks of professionals provide support during the emergency period with effectiveness. As these groups run in virtual environments, we may refer to those as virtual communities of practice. Virtual communities of practice refer to groups of individuals with common interests engaged in informal sharing knowledge and experiences, supporting each other's decisions, experiments, and practices (Wenger, 1998; Hildreth, Kimble \& Wright, 2000; Wenger-Trayner et al., 2014; Henriques, Van-Hout \& Teixeira, 2020). Each informal virtual community of practice has three fundamental elements (Wenger-Trayner et al., 2014; Henriques, Van-Hout \& Teixeira, 2020):

- domain (membership implies commitment and shared competence that distinguishes members from others);

- community (members engage in joint activities and discussions, help each other and share information); and

- practice (members develop a shared repertoire of resources, such as experiences, stories, tools, ways of address problems).

The ICUDDR formed a virtual community of practice to support educators facing difficulties with remote emergency teaching. This virtual community of practice aimed to support educators in addressing the challenges arising from the pandemic crisis. In this article, we present research based on the activities of this Problem-Solving Group.

\section{METHODS}

Based on a Problem-Solving Methodology, the virtual community of practice developed synchronous group sessions and asynchronous individual support. Problem-solving methodologies are processes for analyzing situations or issues that seek and lead to solutions (Mast, 2013; Sheffrey, 2016). The creative optimization of different methodologies may be done for specific applications and knowledge provision (Zhu, Nagalingam 
Figure 1 | Problem-solving methodology within a virtual community of practice

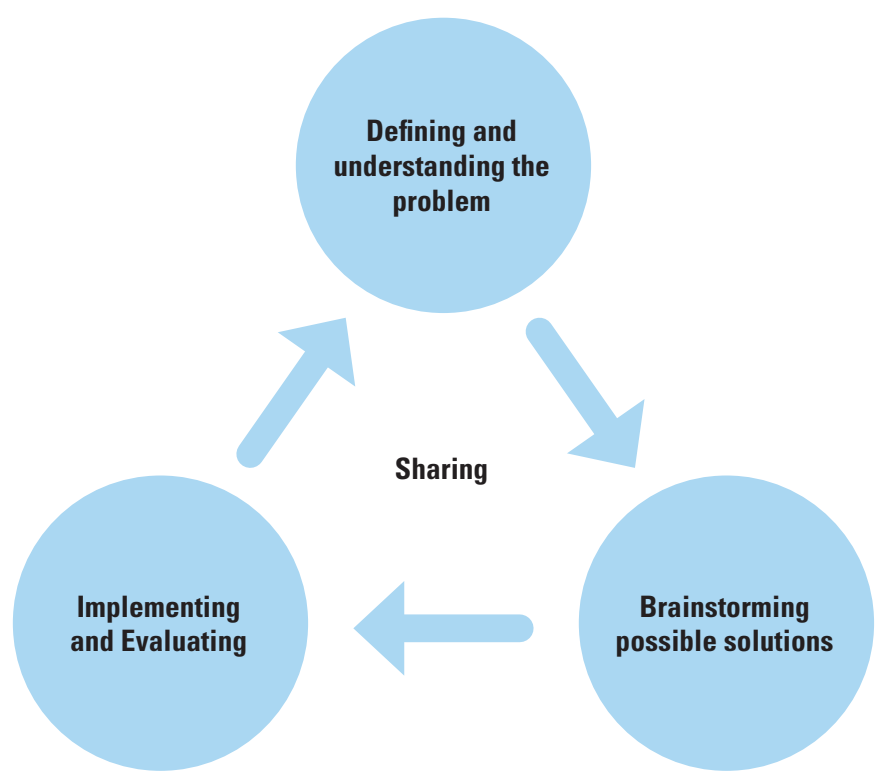

\& Hsu, 2011). Problem-solving methodology within a virtual community of practice comprises fundamental steps: defining and understanding the problem, brainstorming possible solutions, implementing and evaluating, and sharing (Figure 1).

Six Problem-Solving Sessions were held between September and December 2020. Twenty-two individuals participated, mostly professors at the university level, with two facilitators. Professors were mainly female, adults, and were from many parts of the world: USA, Nigeria, the Philippines, Republic of Maldives, Thailand, and Indonesia. The first four sessions were organized around problematic issues raised by participants, while the last two sessions focused on the implementing and evaluating solutions (Figure 2).

The analysis and discussion of the information are based on the Problem-Solving Methodology results. Information was collected during the problem-solving sessions, allowing for a critical description of the steps included in this methodology.

At the end, a post-session survey asking for the participants' opinions was sent out. We used a four-point Likert scale, and participants were invited to indicate their positions on the following aspects: helpfulness/effectiveness of the course; recommendation of this course to a colleague; and changes in remote teaching practices. The survey included some open-ended questions, allowing participants to express their opinions and give suggestions.
Figure 2| Themes of the problem-solving group sessions

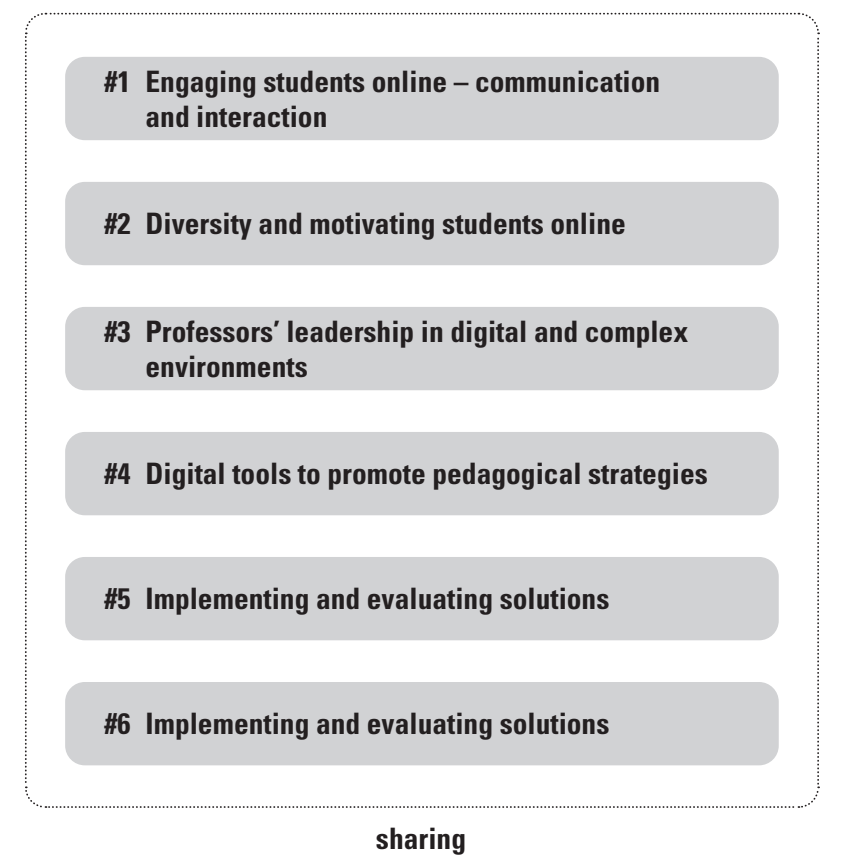

\section{RESULTS AND DISCUSSION}

The pandemic has had global consequences on public health and all dimensions of daily life, particularly in education. The switch to remote forms of teaching and learning brought to light difficulties, challenges, and opportunities. We will discuss some of these from each of the themes based on a problemsolving approach. Such strategy allows for sharing of vivid examples, stories, and experiences.

\subsection{Engaging students online}

The first session focused on engaging students online through communication and interaction. During the group session, a world cloud was built on how to engage students online (Figure 3), identifying different levels of contributions: strategies (such as quizzes, questions, feedback); digital tools (Kahoot, for example); advantages (such as being accessible, empowering, emotional, cheaper); and challenges (such as the need for experience, regular breaks, patience, and assessment).

In the Problem Solving Group, it was necessary to stress the differences between emergency remote teaching and online teaching based on Hodges et al. (2020). Emergency remote teaching has little or no course design over a short period (days or weeks), suboptimal implementation, and temporary access to instruction and supports. Emergency remote teaching also quickly sets up reactive yet reliably available resources. In contrast, online teaching features a robust course design over several weeks or more, high-level implementation, a robust educational ecosystem, and provides rich, detailed resources proactively. 


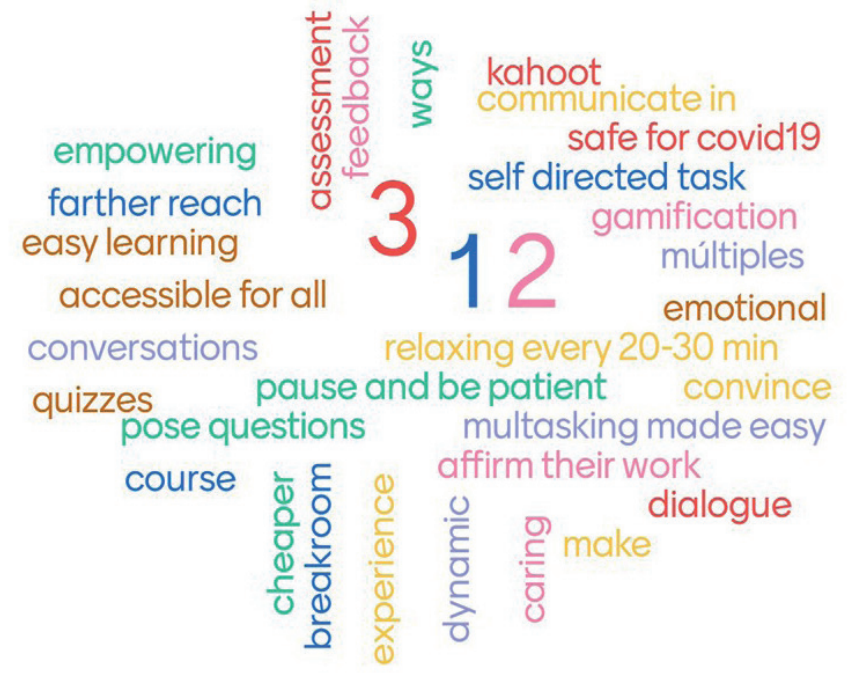

Drawing attention to the intentionality of educational strategies requires a focus on distinctive theoretical approaches to pedagogy. Traditionally, graduate-level curricula have a focus on a discipline's knowledge base and research. For this reason, university-level professors are well-educated in their fields but have few or no pedagogical requirements (Robinson \& Hope, 2013; Cunha, 2004). However, college classrooms are changing due to transformations in learning styles and the incorporation of technology. Thus, educators need instruction in educational theory, methodology, and educational technology (Robinson \& Hope, 2013).

Along with training, it is important to stress that the best teaching is always based on relationships, as knowledge building is based upon interaction. Different types of interaction exist in a student-centered learning process: student-content, studentstudent, and student-professor. The educational process of building knowledge in today's digital societies includes particular communication skills (Bates, 2019):

- using clear language that allows students to understand the information and guidelines regarding the activities they have to perform;

- using a friendly, positive, and familiar tone, creating a positive learning environment;

- planning the communication moments so that they reach students in time (e.g., a message announcing the start of the weekly activities);

- providing proper spaces for asynchronous collaborative communication; guiding, mediating, and directing debates towards learning objectives and contributing to the building shared knowledge and experiences; and

- establishing communication and participation rules for different spaces.

According to Ferri, Grifoni and Guzzo (2020, p. 14), the “... pedagogical challenges are associated with teachers' and learners' lack of digital skills, the lack of structured content versus the abundance of online resources, learners' lack of interactivity and
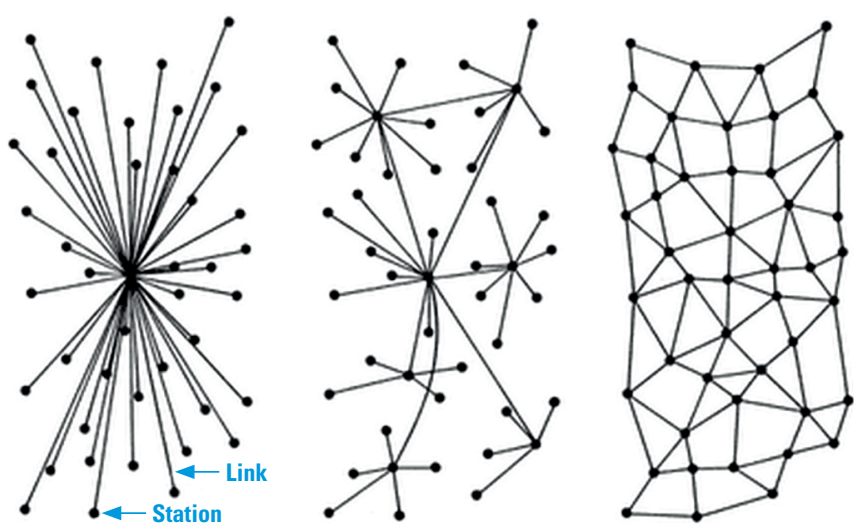

Centralized (A)

Decentralized (B) motivation, and the social and cognitive issues that teachers and schools must address in this situation. The lack of interactivity and motivation of students is connected with the social challenge related to the loss of human interaction between teachers and students as well as among students. In order to encourage children's engagement and curiosity, our results suggest the use of more interactive resources to gamify education...."

\subsection{Diversity and motivating students online}

Learning is a constructive, cumulative, self-regulated (through autonomy), and contextualized process. For learning in an educational setting, what matters is what the learner does. E-activities must align with educational goals and competencies, respond to diversity, and motivate students online. These e-activities must respond to diversity and motivate students online (second Problem-solving session). Research has shown that the best predictors of motivation were: perceived relevance, perceived quality of instruction and learning (the idea that "e-learning is right for me"), reported technology competence, and motivation to begin (Kyong-Jee \& Frick, 2011; Wheeler, 2009).

Technology plays an essential role in these scenarios, enhancing digital integration, developing basic and transversal skills using innovative methods, supporting differentiated strategies based on different levels of interaction. Technology also plays a role in collaboration and knowledge co-construction - centralized (professor is in the centre of teaching and learning process), decentralized (there are several centres with one leader among students), or distributed (it is networking and each one has an equally central role; Figure 4).

Student engagement is more important than motivation in online learning or emergency remote teaching. Engagement requires promoting active learning, building community, helping 


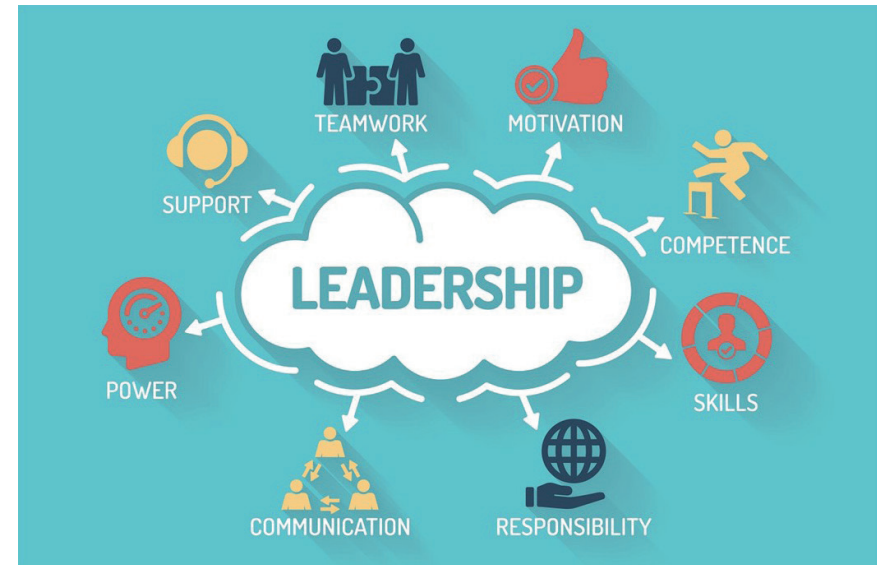

students learn holistically, and ensuring students are appropriately challenged (Barkley \& Major, 2020).

\subsection{Professor' leadership in digital and complex environments}

Education is a complex phenomenon, and educators are leaders within digital environments. Therefore, the third virtual community of practice problem-solving session focused on professors' leadership in digital and complex environments. A phenomenon is considered complex when the interactions between its elements are so many that it is impossible to understand the phenomenon through simple descriptions of its components. The complexity lies in the fact that the components of the systems interact. Through the interaction, they change the system and themselves, creating unpredictable scenarios (Harris \& Jones, 2017).

Educators as leaders in complex digital environments implies "Understanding the collective response to disruptions in the status quo reveals whether system elements now interact in different and perhaps more adaptive ways" (Kershner \& MacQuillan, 2016, p. 7). Leadership is a set of skills, abilities, attitudes, behaviours developed through relational processes between leaders and followers to achieve common goals (Northouse, 2019). E-Leadership focuses on the dialogical dynamics between digital technologies and leadership, that is, how these elements influence each other (Figure 5).

\subsection{Digital tools to promote pedagogical strategies}

Digital tools are fundamental to emergency remote teaching as they allow promoting pedagogical strategies (fourth session virtual community of practice theme). The most important is feeling comfortable with the digital platforms chosen, considering the professor and students as an ecosystem, and promoting transversal skills and regular feedback. Koehler and Mishra (2008, p.12) propose the Technological Pedagogical Content

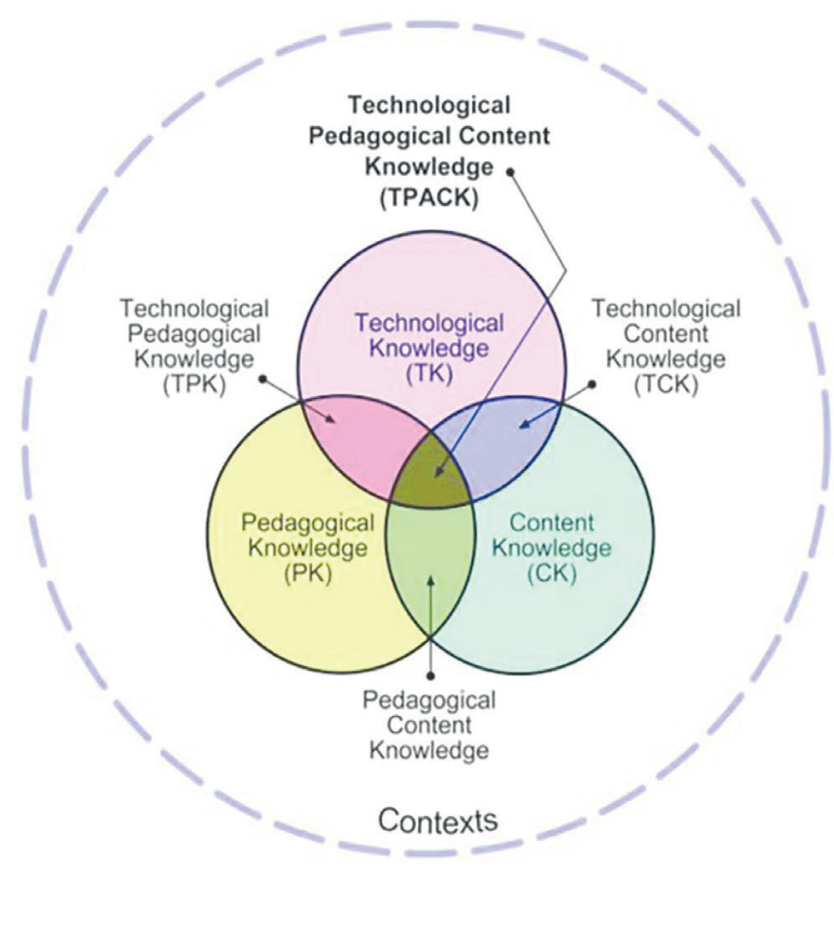

Knowledge (TPCK) model to describe the "knowledge educators need to understand to integrate technology effectively in their classrooms" (Figure 6). This model comprises the complex interaction between content, pedagogy, and technology and is developed by creative, flexible, and adaptive educators that overcome constraints, affordances, challenges, opportunities.

The technological challenges are also related to the unreliability of Internet connections when thousands of people are simultaneously connected, with technological infrastructure in rural areas, and the lack of technological devices or connectivity for many students. There are also problems related to the lack of physical spaces at home where lessons can be received (Ferri, Grifoni \& Guzzo, 2020).

\subsection{Implementing and evaluating solutions}

The four virtual community of practice sessions were complemented with two additional sessions focusing on implementing and evaluating experiences, practices, and strategies (Figure 7). Due to the unexpected shift from face-to-face learning to online, students and educators faced many difficulties. In addition, online educational standards may be a critical issue that needs essential focus. For Hodges et al. (2020) "Online learning carries a stigma of being lower quality than face-to-face learning, despite research showing otherwise. These hurried moves online by so many institutions at once could seal the perception of online learning as a weak option, when in truth, nobody making the transition to online teaching under these circumstances will truly be designing to take full advantage of the affordances and possibilities of the online format". 

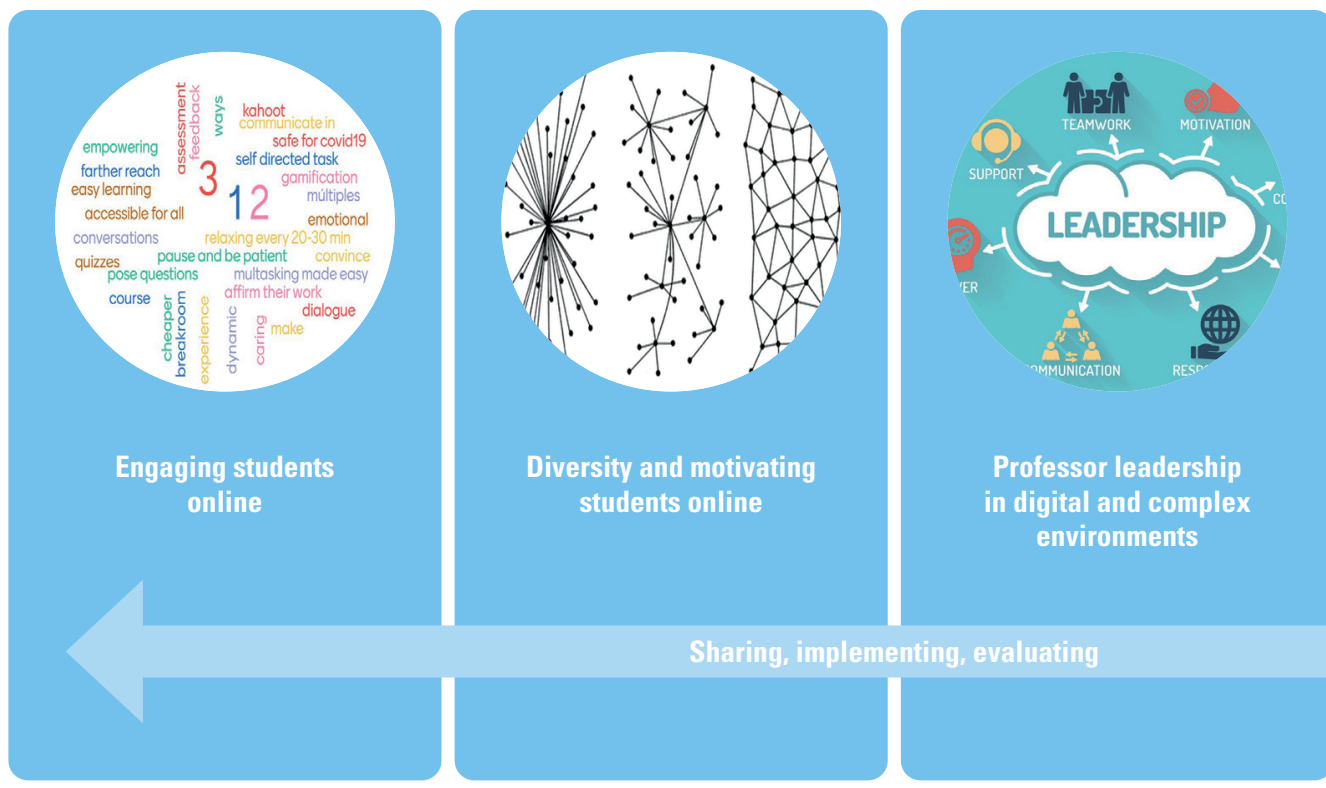

Sharing, implementing, evaluating

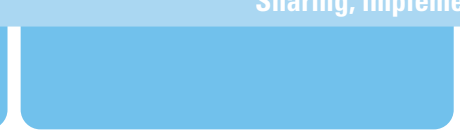

Professor leadership in digital and complex environments

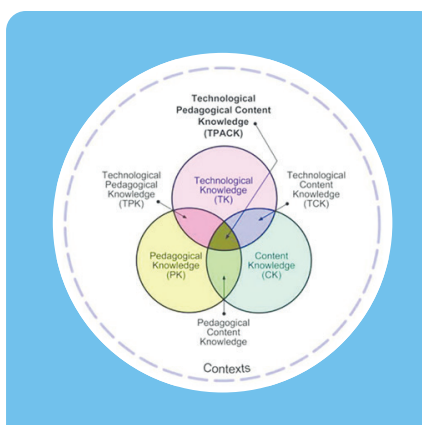

Digital tools to promote pedagogical strategies
According to Ferri, Grifoni and Guzzo (2020, p. 4), it is possible to frame challenges from different natures: technological, pedagogical, and social challenges. Technological challenges refer to access to infrastructures such as technological devices and an Internet connection. Pedagogical challenges highlight teachers' lack of skills in using technology and weakly pedagogical training. Finally, social changes point to a lack of a suitable home learning environment to study and family support.

Participants in these Problem-solving sessions were committed educators who shared their difficulties, experiences, and best practices. The methodology used proved to be adequate and unveiled the critical areas in remote emergency teaching in universities.

Participants were asked to complete a short survey after the course concluded, and the results were analysed. Of the ten people who completed the survey, eight reported finding the course very effective/helpful, one reported it was extremely helpful/effective, and one reported it was not so effective/helpful. When asked to elaborate upon the course effectiveness, one participant stated: "Before, I considered (sic) virtual learning as something very narrow and that which can hardly be effective. The discussion on how to engage students online broadened my understanding and I saw something close to face-to-face learning environment. For example, posing questions and students answering immediately brings about interaction as the teaching is going on, just as in the face-to-face set up. Affirming students in virtual classes can bring about a lot of encouragement, etc."

Another shared: "The course helped me to have new knowledge and to implement practical strategies to eliminate barriers in virtual teaching. The suggestions of facilitators and the participants were valuable and easy to put into practice. For example, how to engage students or clients in virtual learning, and punctuality, teaching strategies, and challenges facing teaching online (digital literacy, technical issues, time management, motivation, passive students, etc.)."

All ten participants reported they were very likely (7) or likely (3) to recommend this course to a colleague. When asked, "Did the Problem-Solving Group change how you teach online/ conduct remote education?”, participants endorsed more positive responses: a great deal (4), a lot (4), a moderate amount (2), with no one endorsing a little or none.

When allowed to share what they would change about the course, several participants stated they wouldn't make changes or would simply like the group to continue. However, some practical suggestions were also provided, such as asking for an "actual demonstration of how to use teaching aids for online learning" and making recordings of the sessions available so participants can watch them again. The session recordings are housed on the ICUDDR website, but perhaps this was not widely advertised to participants.

\section{CONCLUSION}

The results stress the relevance of a common space where educators with similar problems and difficulties can share ideas, experiences, and best practices. The virtual community of practice was effective, although it requires more extensive development and research.

Today we may have favourable conditions to explore innovation through new and creative solutions. However, if they are not transposed and normalized to the system, they will be nothing more than isolated practices and experiences. A culture of in- 
novation must underpin innovation. This means that although we live in a unique moment, the digital transformation will also have to be cultural and social. To transform is not only to transmit but to assume a permanent disruption. Thus, researchers, universities, educational institutions, businesses, and policymakers must all be involved in supplying adequate answers to the challenges emerging from this worldwide experience.

The open challenges emerging from this health emergency may prove crucial in improving the capability to provide effective online learning, evolving educational models to overcome inequalities and isolation in emergencies, and preventing social exclusion. Namely, these problem-solving sessions highlight the following critical aspects:

- Pedagogical training for educators working in universities and colleges;

- Networking and collaborative co-construction of knowledge; and

- Effective integration of technologies in complex educational environments and classroom management.

Educators need support and training, which is most effective when it is close to their needs and perceived problems. Microlearning is a pedagogical model that refers to short courses focused on well-defined objectives and particularly suitable for contextual training and professional development in a perspective of lifelong education (Hug, 2007).

\section{Authors' contributions:}

Both authors proposed the study design, designed the initial form of the manuscript, conducted a survey of current knowledge, and collected relevant sources. Authors conducted the literature review and summary of related work. All authors contributed to the article and approved the final version of the manuscript.

\section{Declaration of interest:}

The authors declare no conflict of interest. 


\section{REFERENCES}

Alvino, F., Di Vaio, A., Hassan, R., \& Palladino, R. (2020). Intellectual capital and sustainable development: A systematic literature review. Journal of Intellectual Capital, 22(1), 76-94. https://doi.org/10.1108/JIC-11-2019-0259

Barkley, E. F., \& Major, C. H. (2020). Student engagement techniques: A handbook for college faculty. Wiley.

Bates, A. W. (2019). Teaching in a digital age - Second edition. Guidelines for designing teaching and learning. Tony Bates Associates Ltd. https://opentextbc.ca/teachinginadigitalage/front-matter/introduction

Cunha, M. A. (2004). Diferentes olhares sobre as práticas pedagógicas no ensino superior: A docência e sua formação. Educação, 3(54), 525-536.

Di Vaio, A., Palladino, R., Hassan, R., \& Alvino, F. (2020). Human resources disclosure in the EU Directive 2014/95/ EU perspective: A systematic literature review. The Journal of Cleaner Production, 257, 120509. https://doi.org/10.1016/j.jclepro.2020.120509

Dias-Trindade, S., Correia, J. D., \& Henriques, S. (2020). Ensino remoto emergencial na educação básica brasileira e portuguesa: A perspetiva dos docentes. Tempos e Espaços em Educação, 13(32), 1-23. https://doi.org/10.20952/revtee.v13i32.14426

Ferri, F., Grifoni, P., \& Guzzo, T. (2020). Online learning and emergency remote teaching: Opportunities and challenges in emergency situations, Societies, 10(4), 86. http://doi.org/10.3390/soc10040086

Harris, A., \& Jones, M. (2017). Middle leaders matter: Reflections, recognition, and renaissance. School Leadership \& Management, 37(3), 213-216. https://doi.org/10.1080/13632434.2017.1323398

Henriques, S., Van Hout, M. C., \& Teixeira, (2020). A virtual 'experiential expert' communities of practice in sharing evidence-based prevention of novel psychoactive substance (NPS) use: The Portuguese experience. International Journal of Mental Health and Addiction. https://doi.org/10.1007/s11469-020-00376-z

Hildreth, P., Kimble, C., \& Wright, P. (2000). Communities of practice in the distributed international environment. Journal of Knowledge Management, 4(1), 27-37.

Hodges, C., Moore, S., Lockee, B., Trust, T., \& Bond, A. (2020). The difference between emergency remote teaching and online learning. Educause Review. https://er.educause.edu/articles/2020/3/the-difference-between-emergencyremote-teaching-and-online-learning

Hug, T. (2007). Didactics of microlearning: Concepts, discourses and examples. Waxmann.

Kershner, B., \& MacQuillan, P. (2016). Complex adaptive schools: Educational leadership and school change. Complicity: An International Journal of Complexity and Education, 13(1), 4-29.

Koehler, M. J., \& Mishra, P. (2008). Introducing TPCK. In AACTE Committee on Innovation and Technology (Ed.), The handbook of technological pedagogical content Knowledge (TPCK) for educators (pp. 2-29). Laurence Erlbaum Associates.

Kyong-Jee, K., \& Frick, T. W. (2011). Changes in student motivation during online learning. Journal of Educational Computing Research, 44(1), 1-23.

http://doi.org/10.2190/EC.44.1.a

Market Research Future. (2020). Online education market size expected to grow at a CAGR over 28.55\% from 2018 to 2023.

https://www.marketresearchfuture.com/press-release/online-education-market

Mast, J. (2013). Diagnostic quality problem solving: A conceptual framework and six strategies. Quality Management Journal, 20(4), 21-36. https://doi.org/10.1080/10686967.2013.11918362

Moreira, J. A., Henriques, S., \& Barros, D. (2020a). Transitando de um ensino remoto emergencial para uma educação digital em rede, em tempos de pandemia [Moving from emergency remore teaching to digital education in times of pandemic]. Dialogia, 34, 351-364. https://doi.org/10.5585/Dialogia.N34.17123

Moreira, J. A., Henriques, S., Barros, D., Goulão, M. F., \& Caeiro, D. (2020b). Educação Digital em Rede: princípios para o design pedagógico em tempos de pandemia. Universidade Aberta. https://doi.org/10.34627/rfg0-ps07
Northouse, P. G. (2019). Leadership: Theory and practice. Western Michigan University. Organization for Economic Co-operation and Development. (2020). Education responses to COVID-19: Embracing digital learning and online collaboration. OECD.

Robinson, T. E., \& Hope, W. C. (2013). Teaching in higher education: Is there a need for training in pedagogy in graduate degree programs? Research in Higher Education Journal, 21.

Shahzad, A., Hassan, R., Aremu, A. Y., Hussain, A., \& Lodhi, R. N. (2020). Effects of COVID-19 in e-learning on higher education institution students: The group comparison between male and female. Quality \& Quantity, 55, 805-826. https://doi.org/10.1007/s11135-020-01028-z

Sheffrey, T. (2016). Back to basics: Solving the problem. Quality Progress, 49(9).

Stoll, L. (2020). Creating capacity for learning: Are we there yet? Journal of Educational Change, 21, 421-430. https://doi.org/10.1007/s10833-020-09394-z

United Nations Educational, Scientific and Cultural Organization. (2020a). Education in a post-COVID world: Nine ideas for public action. UNESCO

United Nations Educational, Scientific and Cultural Organization. (2020b). Education for sustainable development goals: Learning objectives. UNESCO

Wheeler, S. (2009). Learning space mashups: Combining web 2.0 tools to create collaborative and reflective learning spaces. Future Internet, 1(1), 3-13. http://doi.org/10.3390/fi1010003

Wenger, E. (1998). Communities of practice: Learning, meaning, and identity. Cambridge University Press. https://doi.org/10.1017/CB09780511803932

Wenger-Trayner, E., O'Creevy, M. F., Hutchinson, S., Kubiak, C., \& Wenger, B. (2014). Learning in landscapes of practice. Routledge.

Zhu, Z., Nagalingam, S., \& Hsu, H. (2011). Toward a creative problem-solving methodology with knowledge provision. Applied Artificial Intelligence, 25(9), 836-881. https://doi.org/10.1080/08839514.2011.613570 